Check for updates

Cite this: Chem. Commun., 2018, 54, 12507

Received 5th July 2018,

Accepted 15th October 2018

DOI: $10.1039 / \mathrm{c} 8 \mathrm{cc} 05405 \mathrm{c}$

rsc.li/chemcomm

\section{Thiazolidine chemistry revisited: a fast, efficient and stable click-type reaction at physiological $\mathrm{pH} \dagger$}

\author{
Daniel Bermejo-Velasco, ${ }^{a}$ Ganesh N. Nawale, (D) a Oommen P. Oommen, (D) ${ }^{b}$ \\ Jöns Hilborn ${ }^{a}$ and Oommen P. Varghese (D) *a
}

\begin{abstract}
We describe the fast reaction kinetics between 1,2-aminothiols and aldehydes. Under physiological conditions such a click-type reaction afforded a thiazolidine product that remains stable and did not require any catalyst. This type of bioorthogonal reaction offers enormous potential for the coupling of biomolecules in an efficient and biocompatible manner.
\end{abstract}

Conjugation strategies for biomolecules require the design of highly chemoselective, specific and fast bioorthogonal reactions that can produce stable conjugates under physiological conditions without employing any toxic reagents or producing any by-products. ${ }^{1-3}$ In recent years, bioconjugation of functional molecules has received significant attention due to the emerging field of biomedicine that requires covalent conjugation of biomolecules such as nucleic acids, antibodies, proteins as well as glycosaminoglycans to study and manipulate cellular processes. ${ }^{4-7}$ For this purpose, the most commonly employed bioorthogonal reactions include disulfide exchange reactions, ${ }^{8,9}$ Michael addition with $\alpha, \beta$-unsaturated carbonyl compounds, ${ }^{10,11}$ condensation reactions such as hydrazone or oxime formation, ${ }^{12}$ Diels-Alder reactions, ${ }^{13,14}$ click reactions, ${ }^{15-17}$ etc. However, these reactions have several limitations, such as some of the reaction products are sensitive to other nucleophiles such as glutathione present in the milleu, ${ }^{11,18}$ limited stability at physiological $\mathrm{pH},{ }^{19}$ requirement of toxic catalysts such as $\mathrm{Cu}(\mathrm{I})^{20}$ or tedious synthesis of strained olefin substrates. ${ }^{21,22}$ We have recently shown that hydrazone and oxime reactions can be performed at physiological $\mathrm{pH}$ using carboxylic acid as a catalyst or under saline conditions. ${ }^{23,24}$ The hydrolytic stability of such products at physiological $\mathrm{pH}$ could also

\footnotetext{
${ }^{a}$ Translational Chemical Biology Laboratory, Division of Polymer Chemistry, Department of Chemistry-Ångstrom, Uppsala University, Uppsala, Sweden. E-mail: oommen.varghese@kemi.uu.se

${ }^{b}$ Bioengineering and Nanomedicine Lab, Faculty of Biomedical Sciences and Engineering, Tampere University of Technology, and BioMediTech Institute, 33720, Tampere, Finland

$\dagger$ Electronic supplementary information (ESI) available: Experimental details, spectroscopic and analytical data. See DOI: 10.1039/c8cc05405c
}

be improved by tuning the electronic characteristics of the hydrazide moiety. ${ }^{25}$

Reactions involving 1,2-aminothiols are especially interesting because they are naturally present in proteins as $\mathrm{N}$-terminal cysteine. The orthogonal condensation reaction between 1,2-aminothiols and aldehydes to form thiazolidine is an interesting bioconjugation reaction that is poorly explored. Over the years, the thiazolidine chemistry has been explored to develop antibody-drug conjugates ${ }^{26,27}$ as a protecting group for $\mathrm{N}$-terminal cysteines,${ }^{28-31}$ and for developing cyclic peptides. ${ }^{32,33}$ In spite of the large body of literature on the 1,2-aminothiol reaction with aldehydes, there has been limited information on the rate of the reaction and stability of the thiazolidine products under physiological conditions. ${ }^{26,27,34-37}$ It is generally believed that the reaction requires acidic $\mathrm{pH}^{26,35,37-40}$ and a long reaction time, ${ }^{26,27,34-39}$ and that the thiazolidine product is prone to undergo hydrolysis under physiological conditions..$^{26,27,34,40,41}$ A lot of research has been dedicated to achieving stable thiazolidine products by designing different substrates. The most common approach is the preparation of aldehydes having a labile ester in the proximity such that the thiazolidine product can undergo ring rearrangement to afford pseudoproline derivatives. ${ }^{34,41,42}$ Recently, ortho-boronic acid modified benzaldehydes have been prepared to improve the reaction kinetics and to drive the reaction at neutral $\mathrm{pH}^{35,37}$ Since there are conflicting reports on the reaction conditions and product stability, we decided to examine this reaction carefully using a small molecule model and demonstrate its efficacy to conjugate peptides having $\mathrm{N}$-terminal cysteine with aldehydes containing biomolecules that have therapeutic potential.

To evaluate thiazolidine formation under aqueous conditions, we performed the reaction by mixing $\mathrm{L}$-cysteine with a 16 -fold molar excess of propionaldehyde in deuterated phosphate buffer. The ${ }^{1} \mathrm{H}-\mathrm{NMR}$ of the reaction mixture showed a fast and complete conversion to the thiazolidine product at $\mathrm{pD}=5,7.4$ and 9 , as the cysteine resonances were completely disappeared within 5 minutes (Fig. 1 and Fig. S1-S8, ESI $\dagger$ ). At $\mathrm{pD}=3$ thiazolidine formation was considerably slow with complete conversion 


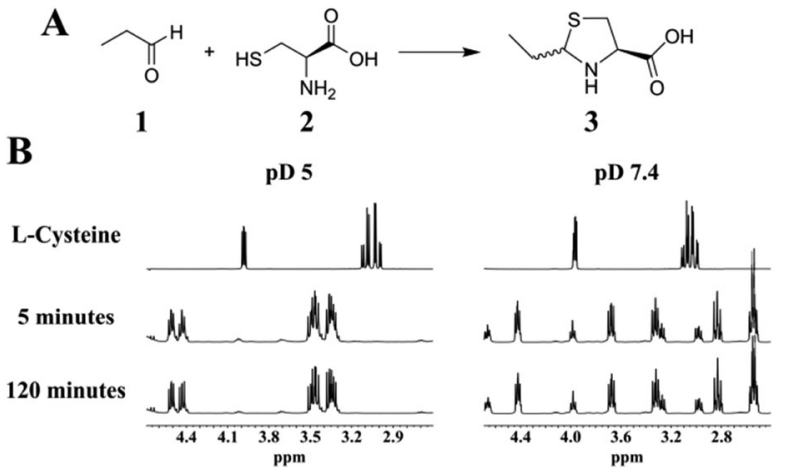

Fig. 1 (A) Scheme of the condensation between propionaldehyde and L-cysteine via thiazolidine formation. (B) Representative ${ }^{1} \mathrm{H}$-NMR spectra at pD 5 and $\mathrm{pD} 7.4$ of the starting material L-cysteine and the reaction mixture recorded after 5 and 120 minutes.

within 30 minutes, which is presumably due to the less nucleophilic amine/thiol groups (Fig. S9 and Fig. S10, ESI $\dagger$ ). These results demonstrate that the reaction between aliphatic aldehydes and 1,2-aminothiols is fast and efficient at a broad range of $\mathrm{pH}(\mathrm{pH}=5-9)$ with millimolar concentrations of the substrates. Interestingly, at neutral $\mathrm{pD}$, we observed acidification of the reaction mixture (decrease in $\mathrm{pD}$ ) as the reaction progressed and therefore an additional base (NaOD) was added to maintain the $\mathrm{pD}$.

The ${ }^{1} \mathrm{H}-\mathrm{NMR}$ analysis of the reaction products revealed different resonances under acidic and neutral conditions. This is presumably due to the deprotonation of the thiazolidine nitrogen that creates a new diastereo center, giving rise to a different splitting pattern of the ${ }^{1} \mathrm{H}-\mathrm{NMR}$ spectra at $\mathrm{pD}$ 7.4. To test our hypothesis of protonation/deprotonation of the amino group, we performed a $\mathrm{pD}$ titration experiment using the purified product $(2 R S, 4 R)$-2-ethylthiazolidine-4-carboxylic acid (3) and observed the reaction using ${ }^{1} \mathrm{H}-\mathrm{NMR}$ analysis at $\mathrm{pD} 5$ and $\mathrm{pD}$ 7.4.

These experiments showed that the species underwent rapid interconversion with the change in PD (Fig. 2 and Fig. S11-S13, ESI $\dagger$ ), confirming that the structure observed at $\mathrm{pD} 7.4$ is indeed a thiazolidine ring structure. We speculate that the multiple splitting patterns observed in ${ }^{1} \mathrm{H}$ NMR at pD 7.4 led to the belief that thiazolidine products are unstable at physiological $\mathrm{pH}$. As a result there are a limited number of examples in the literature where such reactions have been performed under neutral conditions and it is generally suggested that thiazolidine formation requires acidic conditions and the products are unstable under neutral conditions. ${ }^{26,27,34-42}$ We believe that the different intensities of the two sets of signals observed at pD 7.4 are due to the interaction of the carboxylic acid with the syn-NH protons that form a zwitterion which makes the deprotonation of the anti-NH proton more favorable. The structure of the thiazolidine ring was systematically characterized using 1D and 2D NMR spectroscopic analyses with the purified product 3 (Fig. S14-S18, ESI $\dagger$ ).

Once we had established the formation of thiazolidines, we evaluated the stability of the heterocycle at pD 3, 5, 7.4 and 9 using 3 as a model product and examined its integrity

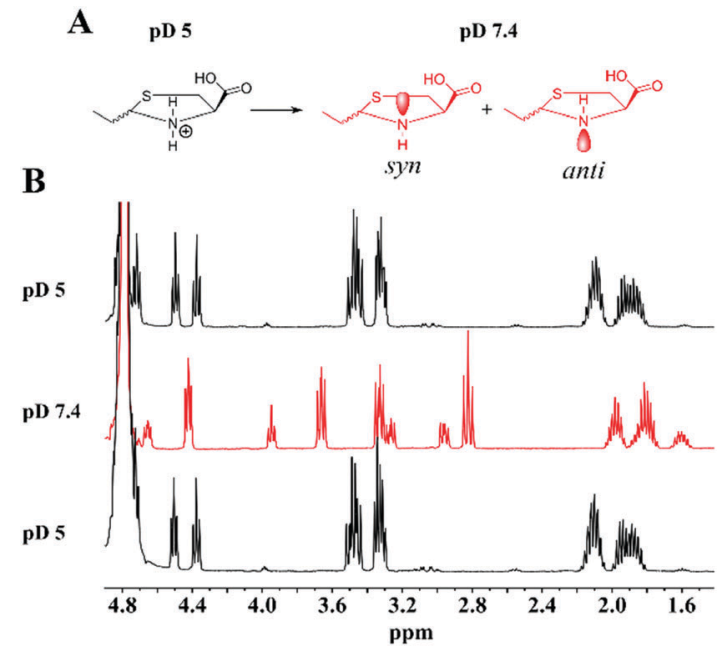

Fig. 2 (A) Schematic representation of the protonation/deprotonation of 3 at pD 5 and pD 7.4. (B) Representative ${ }^{1} \mathrm{H}$-NMR spectra that show the interconversion of the thiazolidine species observed upon $\mathrm{pD}$ adjustment.

periodically via ${ }^{1} \mathrm{H}$-NMR. These studies indicated that the thiazolidine products are extremely stable at the pDs evaluated and revealed no sign of degradation even after 7 days (Fig. S19, ESI $\dagger$ ). The efficiency of thiazolidine formation was extended to different aldehyde substrates under neutral conditions. Aliphatic aldehydes, such as butyraldehyde and trimethylacetaldehyde, showed similar results to propionaldehyde as the reaction was completed within 5 minutes (Fig. S20-S23, ESI $\dagger$ ). With less reactive aromatic aldehydes, such as benzaldehyde and 4-hydroxybenzaldehyde, the reaction was slower and therefore we calculated the rate of the reaction assuming pseudo-firstorder reaction kinetics (Fig. S24 and S25, ESI $\dagger$ ). The rate constant observed for benzaldehyde $\left(k_{1}=0.0146 \mathrm{~min}^{-1}\right)$ was 4.3 -fold higher than that for electron-rich 4-hydroxybenzaldehyde $\left(k_{1}=\right.$ $0.0034 \mathrm{~min}^{-1}$ ). The electron-poor 4-nitrobenzaldehyde could not be studied because it was insoluble under aqueous conditions with $10 \%$ deuterated DMSO. The fast formation kinetics of thiazolidine at neutral $\mathrm{pH}$ and the high stability of the heterocycle formed suggest that such a reaction could be very advantageous for catalyst-free bioconjugation applications.

Encouraged by the positive results, we explored the potential utility of the thiazolidine conjugation chemistry for peptide ligation reactions. For this purpose, we performed a condensation reaction with a model elastin mimetic peptide (CVGVAPG), which contains an N-terminal cysteine residue and propionaldehyde (Fig. 3). The peptide was mixed with different equivalents of propionaldehyde in phosphate buffer saline (PBS, $\mathrm{pH}$ 7.4), keeping the final peptide concentration at $2 \mathrm{mM}$, and the reaction progress was monitored by HPLC.

Similar to what was observed with the small molecule system, the thiazolidine conjugate (retention time 7.8 minutes) was readily formed, and the conjugation was completed in less than $4 \mathrm{~h}$ (as the starting material with a retention time of 6.3 minutes disappeared) with only 1 equivalent of propionaldehyde (Fig. 3B). It is worth mentioning that the above reaction was performed in the absence of dithiothreitol (DTT), which resulted in the peptide dimerization 

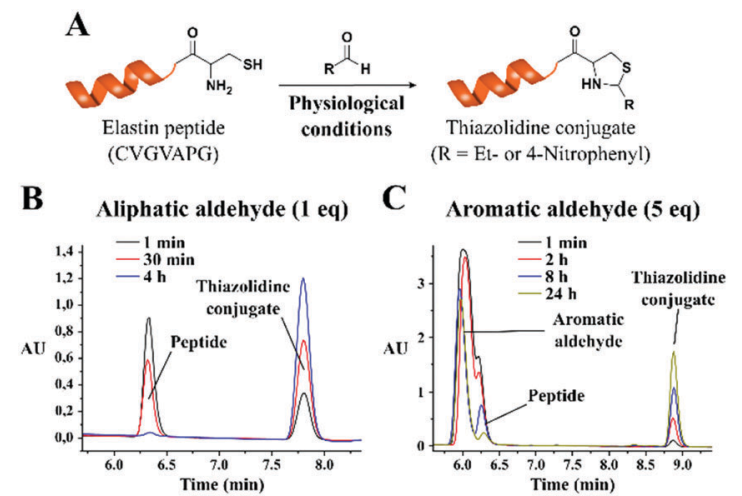

Fig. 3 (A) Schematic thiazolidine condensation between aldehydes and elastin mimetic peptide. HPLC chromatogram showing the conjugation reaction with (B) 1 equivalent of propionaldehyde and (C) 5 equivalents of 4-nitrobenzaldehyde at neutral $\mathrm{pH}$.

due to disulfide formation. When the reaction was performed in the presence of DTT ( $2 \mathrm{mM}$ final concentration), the reaction was complete within 30 minutes with an equimolar concentration of the peptide and aldehyde group (Fig. S26, ESI†). The kinetics of the reaction could be further improved by increasing the peptide/aldehyde ratio. With 2.5 equivalents of propionaldehyde, we observed a faster reaction rate with $75 \%$ conversion within 1 minute (Fig. S27, ESI $\dagger$ ). When the propionaldehyde concentration was further increased to 5 equivalents, we observed $85 \%$ conversion within 1 minute (Fig. S28, ESI $\dagger$ ). When the reaction was performed with an excess of the aldehyde substrate, the formation of disulfide could not be observed, as the reaction rate was extremely fast.

Thereafter we studied the formation of thiazolidines with less reactive aromatic aldehydes using the same peptide and 4-nitrobenzaldehyde as a model substrate. As anticipated, with less reactive aromatic aldehydes we observed a significant decrease in the reaction rate. The reaction was not efficient when the equimolar functionality of aromatic aldehyde was used $(27 \%$ conversion after 24 hours, Fig. S29, ESI $\dagger)$. However, the reaction rate increased with 5 equivalents of aromatic aldehyde. The analysis of the reaction mixture showed $52 \%$ conversion after 8 hours and $87 \%$ conversion after 24 hours (Fig. 3C). With 25 equivalents of aldehyde substrate, the reaction was complete within 8 hours $(77 \%$ conversion after 2 hours, Fig. S30, ESI $\dagger$ ). Of note, all these experiments were carried out in the presence of DTT to avoid disulfide formation.

Further, the versatility of this condensation reaction was demonstrated by developing an oligonucleotide-peptide conjugate. As a model peptide, we used the Tat sequence (CYGRKKRRQRRR), which contains an N-terminal cysteine residue and performed the condensation reaction with a model short interfering RNA (siRNA) that contains an aldehyde modification at the $5^{\prime}$-end. The $\mathrm{N}$-terminal cysteine peptide was added in excess (100 equivalents) to ensure the complete conjugation of the aldehyde modified siRNA $(10 \mu \mathrm{M})$ under physiological conditions. The HPLC chromatogram (monitored at $260 \mathrm{~nm}$ for siRNA) of the reaction mixture showed complete conversion to a thiazolidine conjugated siRNA after 30 minutes (Fig. 4).

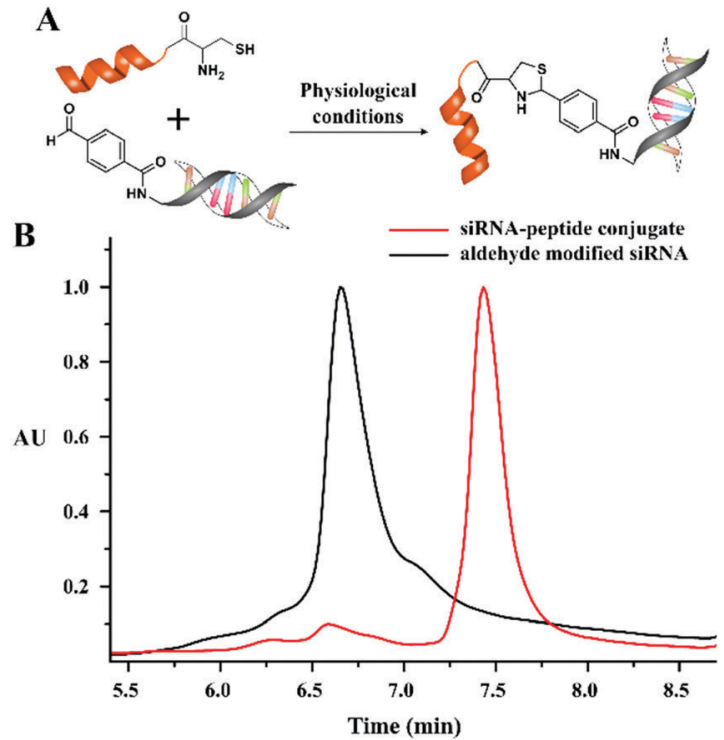

Fig. 4 (A) Schematic thiazolidine condensation between aldehyde functionalized siRNA and Tat mimetic peptide. (B) HPLC chromatogram showing the conjugation of the peptide with the aldehyde modified siRNA.

In summary, we demonstrate for the first time that the condensation reaction between 1,2-aminothiols and aliphatic aldehydes is highly specific and fast under physiological conditions. The obtained thiazolidine product was highly stable at both acidic and neutral $\mathrm{pH}$. The efficiency of such a reaction towards chemical ligation was also demonstrated by coupling peptides with small molecule models as well as oligonucleotides. We believe our results will introduce the thiazolidine click reaction to the forefront of bioconjugation reactions and change the misconceptions regarding thiazolidine formation. This study offers a catalyst-free alternative to click chemistry for conjugating sensitive biomolecules.

This research was funded by the European Commission through the Marie Curie Initial Training Network iTERM (Image materials for Tissue Engineering and Regenerative Medicine) Grant agreement no. 607868.

\section{Conflicts of interest}

There are no conflicts to declare.

\section{Notes and references}

1 E. M. Sletten and C. R. Bertozzi, Angew. Chem., Int. Ed., 2009, 48, 6974.

2 C. P. Ramil and Q. Lin, Chem. Commun., 2013, 49, 11007.

3 D. M. Patterson and J. A. Prescher, Curr. Opin. Chem. Biol., 2015, 28, 141.

4 K. E. Beatty, J. C. Liu, F. Xie, D. C. Dieterich, E. M. Schuman, Q. Wang and D. A. Tirrell, Angew. Chem., Int. Ed., 2006, 118, 7524.

5 G. U. Nienhaus, Angew. Chem., Int. Ed., 2008, 47, 8992.

6 A. Salic and T. J. Mitchison, PNAS, 2008, 105, 2415.

7 M. Grammel and H. C. Hang, Nat. Chem. Biol., 2013, 9, 475.

8 S. I. van Kasteren, H. B. Kramer, H. H. Jensen, S. J. Campbell, J. Kirkpatrick, N. J. Oldham, D. C. Anthony and B. G. Davis, Nature, 2007, 446, 1105.

9 M. H. Stenzel, ACS Macro Lett., 2013, 2, 14. 
10 C. M. Cruz, M. Ortega-Muñoz, F. J. López-Jaramillo, F. HernándezMateo, V. Blanco and F. Santoyo-González, Adv. Synth. Catal., 2016, 358, 3394.

11 M. Z. Chen, N. S. Moily, J. L. Bridgford, R. J. Wood, M. Radwan, T. A. Smith, Z. Song, B. Z. Tang, L. Tilley, X. Xu, G. E. Reid, M. A. Pouladi, Y. Hong and D. M. Hatters, Nat. Commun., 2017, 8,474 .

12 D. K. Kölmel and E. T. Kool, Chem. Rev., 2017, 117, 10358.

13 A. D. de Araújo, J. M. Palomo, J. Cramer, O. Seitz, K. Alexandrov and H. Waldmann, Chem. - Eur. J., 2006, 12, 6095.

14 V. Steven and D. Graham, Org. Biomol. Chem., 2008, 6, 3781.

15 H. C. Kolb, M. G. Finn and K. B. Sharpless, Angew. Chem., Int. Ed., 2001, 40, 2004.

16 C. W. Tornøe, C. Christensen and M. Meldal, J. Org. Chem., 2002, 67, 3057.

17 Q. Wang, T. R. Chan, R. Hilgraf, V. V. Fokin, K. B. Sharpless and M. G. Finn, J. Am. Chem. Soc., 2003, 125, 3192.

18 C.-H. Jung and J. A. Thomas, Arch. Biochem. Biophys., 1996, 335, 61.

19 J. Kalia and R. T. Raines, Angew. Chem., Int. Ed., 2008, 120, 7633.

20 A. E. Speers, G. C. Adam and B. F. Cravatt, J. Am. Chem. Soc., 2003, 125, 4686.

21 J. A. Codelli, J. M. Baskin, N. J. Agard and C. R. Bertozzi, J. Am. Chem. Soc., 2008, 130, 11486.

22 E. M. Sletten and C. R. Bertozzi, Org. Lett., 2008, 10, 3097.

23 S. Wang, D. Gurav, O. P. Oommen and O. P. Varghese, Chem. Eur. J., 2015, 21, 5980.

24 S. Wang, G. N. Nawale, S. Kadekar, O. P. Oommen, N. K. Jena, S. Chakraborty, J. Hilborn and O. P. Varghese, Sci. Rep., 2018, 8, 2193.

25 O. P. Oommen, S. Wang, M. Kisiel, M. Sloff, J. Hilborn and O. P. Varghese, Adv. Funct. Mater., 2013, 23, 1273.
26 G. Casi, N. Huguenin-Dezot, K. Zuberbühler, J. Scheuermann and D. Neri, J. Am. Chem. Soc., 2012, 134, 5887.

27 G. J. L. Bernardes, M. Steiner, I. Hartmann, D. Neri and G. Casi, Nat. Protoc., 2013, 8, 2079.

28 I. E. Gentle, D. P. De Souza and M. Baca, Bioconjugate Chem., 2004, $15,658$.

29 D. Bang, B. L. Pentelute and S. B. H. Kent, Angew. Chem., Int. Ed., 2006, 45, 3985.

30 M. Jbara, S. K. Maity, M. Seenaiah and A. Brik, J. Am. Chem. Soc., 2016, 138, 5069.

31 H. Katayama and S. Morisue, Tetrahedron, 2017, 73, 3541.

32 P. Botti, T. D. Pallin and J. P. Tam, J. Am. Chem. Soc., 1996, 118, 10018

33 A. Zipperer, M. C. Konnerth, C. Laux, A. Berscheid, D. Janek, C. Weidenmaier, M. Burian, N. A. Schilling, C. Slavetinsky, M. Marschal, M. Willmann, H. Kalbacher, B. Schittek, H. BrötzOesterhelt, S. Grond, A. Peschel and B. Krismer, Nature, 2016, $535,511$.

34 A. M. Oelker, J. A. Berlin, M. Wathier and M. W. Grinstaff, Biomacromolecules, 2011, 12, 1658.

35 A. Bandyopadhyay, S. Cambray and J. Gao, Chem. Sci., 2016, 7, 4589.

36 X. Bi, K. K. Pasunooti, A. H. Tareq, J. Takyi-Williams and C.-F. Liu, Org. Biomol. Chem., 2016, 14, 5282.

37 H. Faustino, M. J. S. A. Silva, L. F. Veiros, G. J. L. Bernardes and P. M. P. Gois, Chem. Sci., 2016, 7, 5052.

38 J. Shao and J. P. Tam, J. Am. Chem. Soc., 1995, 117, 3893.

39 L. Zhang and J. P. Tam, Anal. Biochem., 1996, 233, 87.

40 M. Jbara, S. Laps, S. K. Maity and A. Brik, Chem. - Eur. J., 2016, 22, 14851.

41 M. Wathier, C. S. Johnson, T. Kim and M. W. Grinstaff, Bioconjugate Chem., 2006, 17, 873.

42 C. F. Liu and J. P. Tam, PNAS, 1994, 91, 6584. 